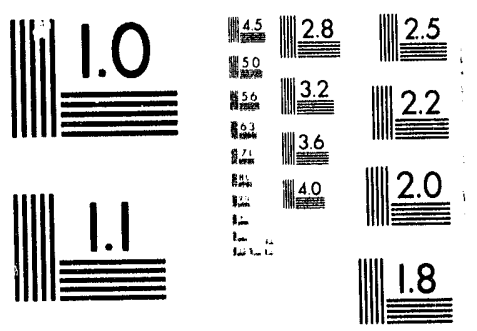

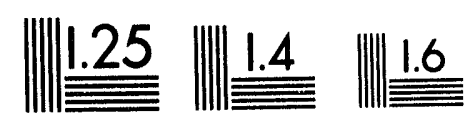





\section{FILMING IN DECONTAMINATION BY MOPPING (U)}

by

W. N. Rankin

Westinghouse Savannah River Company

Savannah River Site

Aiken, South Carolina 29808

P. A. Toole

DOE Contract No. DE-AC09-89SR18035

This paper was prepared in connection with work done under the above contract number with the U. S. Department of Energy. By acceptance of this paper, the publisher and/or recipient acknowledges the U. S. Government's right to retain a nonexclusive, royalty-free license in and to any copyright covering this paper, along with the right to reproduce and to authorize others to reproduce all or part of the copyrighted paper. 


\section{DISCLAIMER}

This report was prepared as an account of work sponsored by an agency of the United States Government. Neither the United States Government nor any agency thereof, nor any of their employees, makes any warranty, express or implied, or assumes any legal liability or responsibility for the accuracy, completeness, or usefulness of any information, apparatus, product, or process disclosed, or represents that its use would not infringe privately owned rights. Reference herein to any specific commercial product, process, or service by trade name, trademark, manufacturer, or otherwise does not necessarily constitute or imply its endorsement, recommendation, or favoring by the United States Government or any agency thereof. The views and opinions of authors expressed herein do not necessarily state or reflect those of the United States Government or any agency thereof.

This report has been reproduced directly from the best available copy.

Available to DOE and DOE contractors from the Office of Scientific and Technical Information, P. O. Box 62, Oak Ridge, TN 37831; prices available from (615) 576-8401.

Available to the public from the National Technical Information Sesvice U. S. Department of Commerce, 5285 Port Royal Rd., Springfield, VA ??151 
SAVANNAH RIVER TECHNOLOGY CENTER WESTINGHOUSE SAVANNAH RIVER COMPANY

WSRC-RP-93-1319

September 28, 1993

Keywords: Decontamination Dilute

CC: L.M. Papouchado, 773-A

W.I Tamosaitis, 773-A

W.E. Stevens, 773-A

J.R. Chandler, 703-H

J.E. Marra, 703-H

T.H. Hsu, 703-H

R.J. Hinds, 773-A

SRTC Records (4)

TO:

FROM:

R.H. Hsu, 773-43A

W.N. Rankin, 773-A

P.A. Toole, 773-A

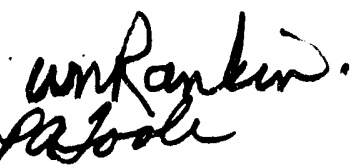

FIIMING IN DECONTAMINATION BY MOPPING (U)

\section{INTRODUCTION AND SUMMARY}

Technical assistance was provided High Level Waste Engineering in the investigation and prevention of filming during decontamination by mopping. After moping operations in a Tank Farm application, a film of the cleaning ahich sometimes remained on the surface being cleanedence interfered with monitoring to detect the presence of radioactive material.

scoping tests were conducted to investigate filming characteristics of two cleaning materials. In addition, rinsing tests were conducted to demonstrate how filming can be prevented.

Results are that filming with both dilute (2 volume percent) and concentrated (full strength) Isoclean solutions occur when surfaces cleaned by decontamination by mopping are not properly rinsed immediately after cleaning. Fitely $1 / 2$ pint prevented by flooding the surface with approximately, followed of water per square foot immediately after cleaningot occur by dry mopping. To insure that filming wil several times. flooding and dry mopping could be repeated isoclean, affects the Irradecon 210 , an alternative to Isoclean, affect 
paint used in this Tank Farm application. It should not be used to clean this surface without further investigation.

\section{BACKGROUND}

A problem was encountered in using concentrated Isoclean, a liquid detergent marketed by Isolab, Inc. (800) 321-9632, in decontamination efforts around riser B6 on Tank top 35. After clecontamination efforts were completed a film of Isoclean remained on the surface. This film prevented the detection of transferable contamination under the film by using dry smears. Later the area was smeared using Massin cloth, a rough, oil saturated cloth used for detecting transferable contamination. The Massin cloth broke through the film and revealed the presence of the smearable contamination under the film.

We met with Vernon Davis of Waste Management on 7/30/93 to view Tank 35 and to learn more about what occurred. The area consists of both concrete and carbon steel, painted with Glidden Latex House and Trim paint. Full strength and diluted Isoclean are routinely used. Isoclean is typically applied with atomic wipes or mops, and is removed by dry wiping or dry mopping the surface.

A more effective, environmentally acceptable alternative to Isoclean may exist. Previous decontamination demonstrations conducted by SRTC/IWT has shown the effectiveness of Iradecon 210, a biodegradable, solvent/degreaser cleaner marketed by Decon Laboratories, Inc. (800) 332-6647. Waste generated from using Iradecon 210 in decontamination applications are not expected to be classified as mixed waste.

\section{DISCUSSION}

1. Eilming Tests - Scoping tests were conducted using both Isoclean and Iradecon 210 on carbon steel specimens painted with Glidden Latex House and Trim paint. The tests were conducted to investigate the filming characteristics of Isoclean and Iradecon 210.

\section{Experimental Procedure}

- Tests were conducted on 1 in. by 3 in. painted carbon steel coupons. The same paint that was used on the Tank 35 riser, Glidden Flat Latex House and Trim paint, was used. (The surface of the paint was involved in the decontamination. The substrate material would not be expected to have any effect). 
- Approximately $0.5 \mathrm{ml}$ of a sodium hydroxide solution with a $\mathrm{pH}$ of approximately 14 was applied to the center of one face of the specimens and allowed to dry. The contaminant on Tank 35 had a similar pH. It could have affected the properties of the paint.

- Two concentrations of Isoclean and Iradecon 210 were used. Dilute solutions were prepared following the manufacturer's instructions (2 volume percent Isoclean, 50 volume percent Iradecon 210). Concentrated solutions consisted of the full-strength materials directly from the bottles. A small amount of Methyl Orange Indicator manufactured by Betz (215) 355-3300 was added to aid in the observation of filming.

- Solutions were applied to the face of the specimens with a single swipe with an "atomic wipe" saturated with the solution. The solutions were allowed to remain on the surface of the coupon for 10 minutes.

- A second "atomic wipe" was used to remove the decontamination solutions from the specimens. Both wet and dry "atomic wipes" were used. The surface of the coupons were wiped using both single and double swipes.

- All specimens were allowed to dry. They were wiped again with a dry "atomic wipe" using both single and double swipes.

- All specimens were examined visually for filming.

\section{Results}

- Half of the face of all specimens were wiped using Maslin cloth.

- All specimens were examined visually for filming.

- Eilming occurred on all specimens. The degree of filming typically varied with the concentration of the cleaning solution and with the method of wiping the surface after cleaning. Heavier filming generally occurred with the concentrated solutions (fullstrength materials directly from the bottles). Light filming generally occurred with the dilute solutions (prepared following the manufacturer's instructions). Heavier filming typically occurred with surfaces wiped with dry "atomic wipes" vs. wet "atomic wipes." No 
effect was observed of the sodium hydroxide on the properties of the painted surface.

- Once a film forms it cannot be easily removed by dry or wet wiping.

- The filming characteristics of Iradecon 210 appear to be similar or worse than those of Isoclean.

2. Rinsing Tests - Scoping tests were conducted using both Isoclean and Iradecon 210 on carbon steel specimens painted with Glidden Latex House and Trim paint. The tests were conducted to demonstrate how filming can be prevented.

\section{- Experimental Procedure}

- Tests were conducted using coupons prepared the same as those used in the previous test.

- Tests were conducted with the same cleaning solutions used in the previous tests.

- Specimens were cleaned by making three swipes with an "atomic wipe" saturated with the cleaning solution.

- Imrnediately after cleaning the surface of the specimen was flooded with water using a squirt bottle. (The volume of water used to flood the 3 square inch surface of the specimen was estimated to be $5 \mathrm{ml}$. This is equivalent to approximately $1 / 2$ pint of water per square foot of surface area).

- Immediately after the surface was flooded with water, it was dried by wiping three times with a dry "atomic wipe."

- P.fter they had dried in air the surface of all specimens were examined visually for filming.

\section{Results}

- The Iradecon 210 solutions adversely effected the surface of the paint. This could be due to an organic solvent in this material. The filming observed in the first test could have actually been smearing of the surface of the paint that had been softened by contact with the cleaner/degreaser.

- No filming was observed on the surfaces of any specimens cleaned with either concentrated or dilute 
WSRC-RP - 93-1319

September 28, 1993

Page 5

Isoclean followed immediately by flooding the surface with water and drying with a dry "atomic wipe."

\section{CONCLUSIONS}

- Filming occurs when surface cleaned by decontamination by Isoclean and mopping are not properly rinsed immediately after cleaning.

- Filming can be prevented by wetting the surface with water immediately after cleaning, followed by dry mopping. Only approximately $1 / 2$ pint of water per square foot is required to flooding the surface. Subsequent dry wiping removes enough residual cleaning solution to prevent filming. To insure that filming will not occur, flood and dry mopping could be repeated several times.

- Iradecon 210 affects the properties of Glidden Flat Latex House and Trim paint and should not be used to clean this surface withour further investigation. 

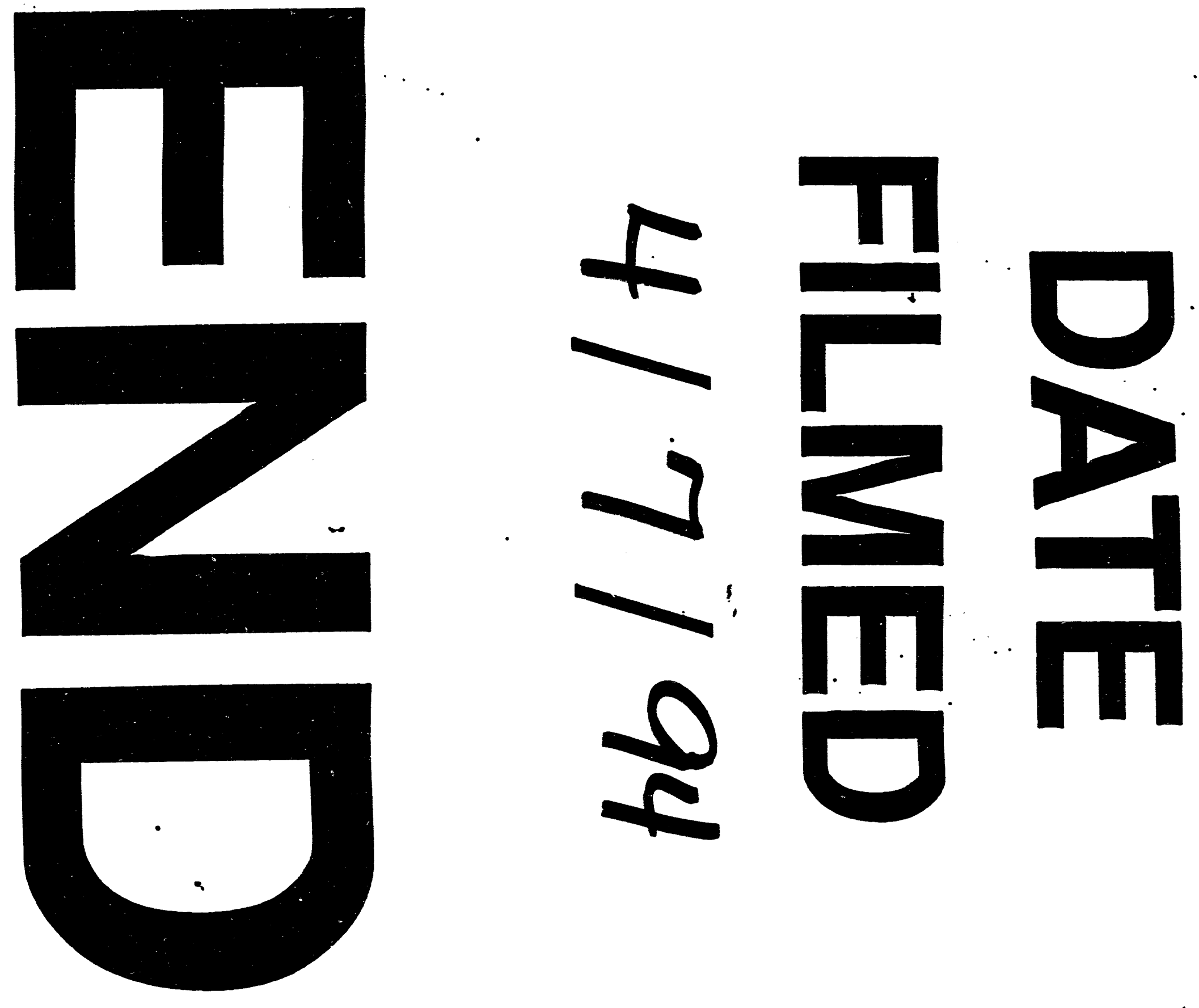


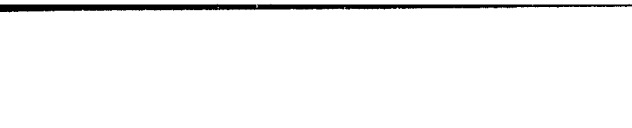

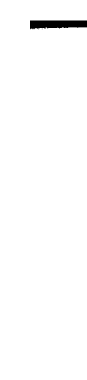

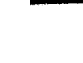

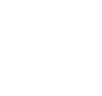
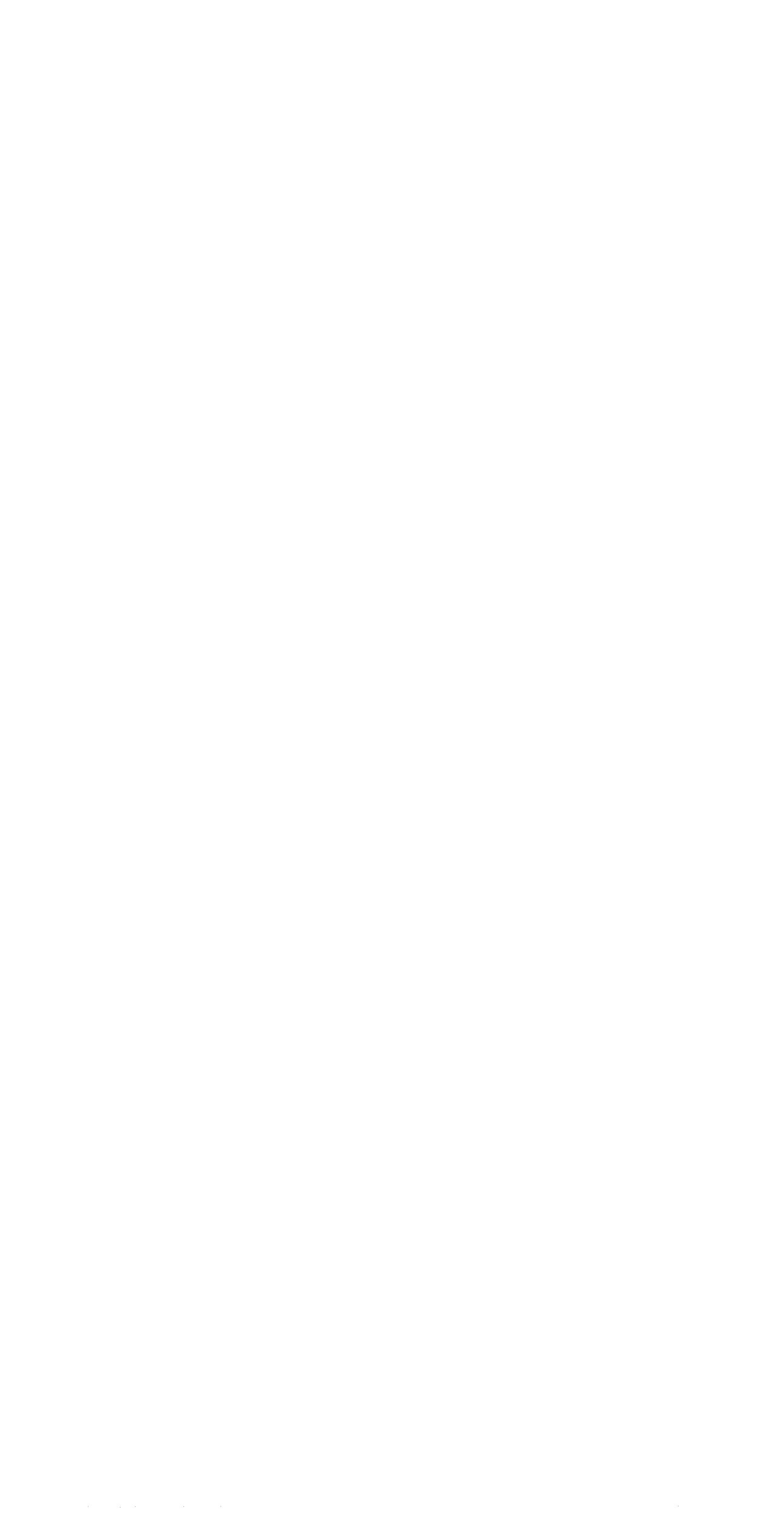